\title{
629
}

Gasen vollkommen sicher wäre, und die Grölsen $m, s$, $k$, $a$ alle vier bestimmt hätte, was immer gut seyn möchte, würde man doch, allgernein gesprochen, durch das Resultat der Analyse allein keine absolute (Gewifsbeit erhalten, dafs die vorausgesetzten Gase auch wirklich in dem zerlegten Gemenge vorbanden waren. $P$.

\section{Ueber das Verhalten einiger Silbersalze im Wasserstoffyas.}

(Aus einem Briefe des Prof. Wöhler an den Herawgeber.)

- Bei einigen Untersuchungen über die eigentliche $\mathrm{Zu}$ sammensetzungsweise der Honigsteinsäure, machte ich die Beobachlung, dafs das Silbersalz dieser Säure, bei $100^{\circ}$ der Einwirkung von reinem Wasserstoffgas ausgesetzt, seine weifse Farbe sehr rasch in eine scluwarze umänderte, und nachher mit einer intensiv rothgelben. Farbe in Wasser löslich war. Es wurde bierbei etwas Wasser gebildet, und das Salz erlitt einen Gewichtsverlust, der dem balben Sauerstoffgehalt des Oxyds eutsprach. Die braune Auflösung des veränderten Salzes war stark sauer, und setzte nach kurzer Zeit einen Spiegel ron metallischen Silber ab, indem sie sich entfärbte und hierauf das gewöbnliche farblose Silbersalz in der freien Säure aufgelöst en!hielt.

Dieses Verhalten deutete mit grofser Wabrscheinlichkeit darauf hin, dafs bei der Einwirkung von $W$ asserstoffgas auf das Silberoxydsalz dieses zu einem Oxydulsalz reducirt worden sey, eine Vermulhuog, die ich bei Untersuchung des Verhaltens noch anderer Silbersalze vollkommen bestätigt fand, und wodurcb also die Existenz eines Silberoxyduls, $=\dot{A} g$, mit Bestinuntheit nachgewiesen worden ist. Dic meisten Silbersalze, nament- 
lich die mit organischen Säuren, scheinen sich ähnlich zil verhalıen, und die Kenntnifs dieses Ümstandes künnte vielleicht auch in manchen Fällen bei Bestimnnung des Wasserverlustes, den organische Substanzen in Verbindung mit Silberoxyd erleiden, in Betracht kommen.

Unter dea übrigen Silbersalzen, die ich auf diese Weise väher untersucht habe, zeigte sich die Veränderung am deutlichsten bein citronensauren Silberoxyd. Bei $100^{\prime \prime}$ eineen Stroin von getrochnetern Wasserstoffgas ausgesetzt, wird es sehr rasch durch seine ganze Masse hindurch dunkelbraun. I)ie Wirkung fangl, wie auch bein honigsteinsauren Salz, selbst schon bei gewöbnlicher Temperatur an. $k$ s ist nun ein (remenge von cilronensaurem Oxydulsalz und freier Citronensiure. Von 2 Atongewichten Oxydsalz geht die Hälfte des Suuerstoffs voun Silberoxyd als Wasser weg, es bildet sich $\mathrm{Ag}^{2} \mathrm{O}$, welches init der einen Hälfte der Säure verbunden bleibt, wäbrend die andere frei wird. Wasser zielit die freie Säure aus, und sobald diese grofsentheils entfernt ist, fängt das Oxydulsalz an sich mit tiefer Portweinfarbe in dein reinen Wasser anfzulusen. In trockneın Zustande ist dieses Salz ein sibwarzbraunes Pulver. Bein Erhitzen zerselzt es sich unter viel schwächerer Verpuffurig als das weilse Oxydsalz. Es hitterliilst dabei 76 Procent metallisches Silber, was die Menge ist, die nach der Formel $\dot{A g}_{g} \mathrm{C}^{7} \mathrm{H}^{7} \mathrm{O}^{*}$ zurïckbleiben unufs.

Wird die rothe Auflösung des Oxydulsalzes gekocht, so wird sie unter schwacher (iasentwichlung allmälig zerselzt, sie nimmt eine eigenthümliche, gelblichgrüne und blauschillernde Farbe an, setzt später inetallisches Silber ab und wird farblos. In Ammoniak löst sich das braune Oxydulsalz mit einer ebenfalls sehr intensiven rothgelben Farbe auf. Beim F.rhizen erleidet die Auflösung eine ähnliche Zersetzung wie die vorhergebende. Zuweilen bekleiden sich dabei die Wünde des Gefälses mit einem glänzenden, fast vollkommen goldfarbenen, me- 


\section{1}

tallischen Ueberzuge, der, wie fein vertheiltes Gold, nit schön grüner Farbe durchscheinend ist. Bein Erbilzen wird diese Substanz in weifses metallisches Silber verwandelt.

Aus der rothen Auflösung des Silberoxydulsalzes fällt Kali, unter Entfärbung derselben, ein vollk ommen schwarzes, schweres Pulver. Man erbält es auch durch unwittelbare Zersetzung des trockuen Salzes mit Kalilösung. Es bleibt nach dem Trocknen schwarz, nimmt durch Druck vollkommen dunkeln Metallglanz an, und wird bein Erhitzen, unter Entwicklung von Sauerstoffgas, zu weifsem Silber. Die bestiminte schwarze Farbe scheint dafür zu sprechen, dafs es das reine Silberoxydul ist. Indessen ist es eigentlich nur die bestimmte schwarze Farbe, die dafür spricht; denn seinem Verhalten nach könnte es eben so gut ein in deun Abscheidungsmoment aus dem Oxydul entstandenes inniges Gemenge von Silberoxyd und metallischeun Silber seyn. Mit Säuren zerfallt es sogleich in Metall und Oxydsalz; eben so mit Aınnoniak. Von Chlorwasserstoffsäure wird es in eine braune Substanz verwandelt, die entiveder das dem Oxydul proportiouale Chlorür, oder ebenfalls nur ein Gemenge von Silber und gewöhnlichem Chlorsilber ist. Man erbält sie auch, als einen braunen, käsigen, sich rasch ansaminelnden Niederschlag, durch Fällung der rothen Auflösung des citronensauren Oxydulsalzes init Salzsäure. Durch Druck nimnt sie Metallglanz an. Bis zu der Teinperalur erhitzt, wobei Cblorsilber schmilzt, sintert sie nur zusamınen, wird gelb, und ist jedenfalls alsdann ein Genenge von Silber mit. gewöhnlichem Chlorsilber geworden. Mit Amınoniak, and selbst mit einer concentrirten Salıniaklösung, zerfält das braune Chlorür sogleich in sich auflösendes Culorsilber und in zurückbleibendes Metall.

Oxalsaures Silberoxyd, bei $100^{\circ}$ der Einwirkung von Wasserstoffgas ausgesetzt, wird hell bräunlich gelb; 


\section{2}

aber die Zersetzung scheint bei dieser Temperatur nur partiell zu bleiben. Bei $140^{\circ}$ wurde es braun, gleich darauf aber entstand eine sehr heftige Explosion. Bernsteinsaures Silberoxyd wurde bei $100^{\circ}$ in Wasserstoffgas citrongelb. Bei etwas höberer Temperatur sublimirte die Hälfte der Bernsteinsäure davon ab. Das so gebil. dete bernsteinsaure Silberoxydul ist in Wasser unlöslich. Reines Silberoxyd wird in Wasserstoffgas genau bei $100^{\circ}$ zu Metall reducirt.

X. Ueber die Schwärzung des salpetersauren Silberoxyds durch Licht.

Auf der letzten Versammlung britischer Naturforscher, zu New - Castle, theilte Hr. Scanlan folgende Erfahrung mit. Er nabm zwei Staugen von ganz reinem gegossenem salpetersaurem Silberoxyd, so wie sie unmittelbar aus der Form gekonmen waren, wickelte die eine in Papier, und brachte die andere, miltelst eines Glasstabes, in eine Glasriobre, die er darauf vor dem Löllirobr vorsichtig zuschınolz, so dals durchaus keine Berübrung mit organischen Substanzen stattfand. Nach drei Tagen wickelte er die erste Stange aus dem Papier, und schlors sie ebenfalls bermetisch in eine Glasröhre. Darauf legte er beide Röhren in Sonnenschein. Die mit Papier in Berührung gewesene Stange schwärzte sich schun uach einer halben Stunde, die andere aber war nucb nach sechs Wochen vollkommen werfs '). Hieraus erhellt, dafs̉ salpetersaures Silberoxyd, bei gänzlichem Ausschlufs organischer Substanzen (die immer, wie Schwefelwasserstoff zuweilen, in der Luft vorhanden sind) vom Licht nicht geschwïrzt wird. (Alhenaeum, No. 565 p.597.)

1) Ich selbst sah sie bei Hrn. Scanlan.

p. 